\title{
Seizure outcome in pediatric medically refractory temporal lobe epilepsy surgery: selective amygdalohippocampectomy versus anterior temporal lobectomy
}

\author{
Cameron A. Elliott, MD, ${ }^{1}$ Andrew Broad, BSc, ${ }^{1}$ Karl Narvacan, BSc, ${ }^{1}$ Trevor A. Steve, MD, ${ }^{2}$ \\ Thomas Snyder, PhD, ${ }^{3}$ Jordan Urlacher, $\mathrm{PhD},{ }^{3} \mathrm{~B}$. Matt Wheatley, MD, PhD, ${ }^{1}$ and \\ D. Barry Sinclair, MD $^{4}$
}

Divisions of ${ }^{1}$ Neurosurgery, ${ }^{2}$ Neurology, ${ }^{3}$ Psychiatry, and ${ }^{4}$ Pediatric Neurology, University of Alberta, Edmonton, Alberta, Canada

OBJECTIVE The aim of this study was to investigate long-term seizure outcome, rate of reoperation, and postoperative neuropsychological performance following selective amygdalohippocampectomy (SelAH) or anterior temporal lobectomy $(A T L)$ in pediatric patients with medically refractory temporal lobe epilepsy (TLE).

METHODS The authors performed a retrospective review of cases of medically refractory pediatric TLE treated initially with either SelAH or ATL. Standardized pre- and postoperative evaluation included seizure charting, surface and longterm video-electroencephalography, 1.5-T MRI, and neuropsychological testing.

RESULTS A total of 79 patients treated initially with SeIAH $(n=18)$ or ATL $(n=61)$ were included in this study, with a mean follow-up of $5.3 \pm 4$ years (range 1-16 years). The patients' average age at initial surgery was $10.6 \pm 5$ years, with an average surgical delay of $5.7 \pm 4$ years between seizure onset and surgery. Seizure freedom (Engel I) following the initial operation was significantly more likely following ATL $(47 / 61,77 \%)$ than SelAH $(8 / 18,44 \% ; p=0.017$, Fisher's exact test). There was no statistically significant difference in the proportion of patients with postoperative neuropsychological deficits following SelAH (8/18, 44\%) or ATL (21/61,34\%). However, reoperation was significantly more likely following SelAH (8/18, 44\%) than after ATL $(7 / 61,11 \% ; p=0.004)$ and was more likely to result in Engel I outcome for ATL after failed SelAH (7/8, 88\%) than for posterior extension after failed ATL $(1 / 7,14 \% ; p=0.01)$. Reoperation was well tolerated without significant neuropsychological deterioration. Ultimately, including 15 reoperations, 58 of 79 (73\%) patients were free from disabling seizures at the most recent follow-up.

CONCLUSIONS SelAH among pediatric patients with medically refractory unilateral TLE yields significantly worse rates of seizure control compared with ATL. Reoperation is significantly more likely following SelAH, is not associated with incremental neuropsychological deterioration, and frequently results in freedom from disabling seizures. These results are significant in that they argue against using SelAH for pediatric TLE surgery.

https://thejns.org/doi/abs/10.3171/2018.4.PEDS17607

KEYWORDS epilepsy surgery; reoperation; neuropsychology

S URGERY is now the mainstay of effective treatment for pediatric medically refractory temporal lobe epilepsy (TLE). ${ }^{3-5,8,10,13,14,18,25,26,29}$ However, considerably less is known about the impact of resection strategy on outcomes in pediatric epilepsy surgery patients as compared to their adult counterparts. ${ }^{16,19,28}$ Selective amygdalohippocampectomy (SelAH) for pediatric patients with complex partial seizures demonstrated to be of mesial temporal origin with concordant clinical imaging and electrographic findings remains a viable surgical option at many institutions, including ours, especially when operating on the dominant side. . $^{1,6,11,12,17,27}$ It is thought to

ABBREVIATIONS ATL = anterior temporal lobectomy; EEG = electroencephalography; FMA = figure memory average; $M T G=$ middle temporal gyrus; $M T S=$ mesial temporal sclerosis; PRI = perceptual reasoning index; SEEG = stereoelectroencephalography; SelAH = selective amygdalohippocampectomy; TLE = temporal lobe epilepsy; $\mathrm{VCl}=$ verbal comprehension index; $\mathrm{VMA}=$ verbal memory average.

SUBMITTED November 6, 2017. ACCEPTED April 17, 2018.

INCLUDE WHEN CITING Published online June 22, 2018; DOI: 10.3171/2018.4.PEDS17607. 
have the same surgical outcome with less neuropsychological deficit. ${ }^{15,23,28}$ However, the existing literature examining postoperative seizure control after pediatric SelAH reports divergent rates of postoperative freedom from disabling seizures (Engel I), ranging from $33 \%$ to $87 \%$. $^{2,4-6}$, ${ }^{20,23}$ These divergent data are difficult to synthesize due to heterogeneity in duration of postoperative seizure surveillance, ultimate histopathological diagnosis, presence of dual pathology, surgical approach, sample size, postoperative weaning of antiepileptic medications, and neuropsychological testing. ${ }^{5}$

Therefore, our motivation for this study was based on observations over time at our institution that among pediatric patients with disabling, medically refractory TLE, SelAH results in worse seizure control and higher likelihood of reoperation compared to ATL. The primary objective of this study was to compare seizure control and rate of reoperation for ongoing or recurrent seizures among pediatric patients with disabling, medically refractory TLE operated on with either SelAH or ATL, using a retrospective single-center review. Our secondary objective was to evaluate neuropsychological performance after initial and any subsequent epilepsy surgeries.

\section{Methods \\ Patients}

A retrospective review of pediatric TLE surgery for medically refractory epilepsy was performed at the Comprehensive Epilepsy Program at the University of Alberta for the period between 1988 and 2015. This study was approved by the University of Alberta Health Research Ethics Board. Descriptive characteristics of the 79 identified patients are shown in Tables 1 and 2.

\section{Preoperative Evaluation}

All patients underwent a standardized preoperative assessment, including clinical evaluation, seizure log, continuous noninvasive scalp electroencephalography (EEG; baseline EEG and long-term video-EEG with 32 leads [16 channels] on either system), and neuroimaging (1.5-T MRI in all but 8 patients; interpreted by a pediatric neuroradiologist). Hippocampal relaxometry and volumetry were not performed. Preoperative neuropsychological testing was carried out by an experienced pediatric neuropsychologist (T.S.). Ancillary neuroimaging was performed if indicated, including ictal and interictal SPECT (using either hexamethyl propylene amine oxime [HMPAO] or technetium-99m HMPAO) in 11 patients. Tracer was injected within 5 minutes of the seizure, and an ictal scan was performed within 2 hours of injection. Stereoelectroencephalography (SEEG) was performed selectively (in 3 cases) to further assist with lateralization or localization of epileptic focus. Intracarotid sodium amytal testing was performed in 14 cases in which involvement of the dominant hemisphere was queried. In other cases hemispheric dominance was established based on handedness alone (60 cases), fused dichotic listening test (4 cases), or functional MRI (1 case). Each case was presented prior to surgery at an institutional epilepsy conference.
TABLE 1. Demographic and clinical characteristics of 79 pediatric patients referred for surgery for TLE

\begin{tabular}{|c|c|}
\hline Characteristic & Value \\
\hline Sex: male & $45(57 \%)$ \\
\hline Handedness: right & $67(85 \%)$ \\
\hline Mean age at onset (yrs) & $5.1 \pm 5.0$ \\
\hline Mean age at operation (yrs) & $10.6 \pm 5.3$ \\
\hline Mean duration of surgical delay (yrs)* & $5.7 \pm 4.3$ \\
\hline Mean postop seizure follow-up (yrs) & $5.3 \pm 3.8$ \\
\hline \multicolumn{2}{|l|}{ Semiology } \\
\hline Auras & $35(45 \%)$ \\
\hline Simple partial seizure & $12(15 \%)$ \\
\hline Complex partial seizure & $61(78 \%)$ \\
\hline Generalized seizure & $11(14 \%)$ \\
\hline \multicolumn{2}{|l|}{ History } \\
\hline Family history of epilepsy & $20(25 \%)$ \\
\hline Febrile seizures & $17(22 \%)$ \\
\hline Head trauma & $8(10 \%)$ \\
\hline Asphyxia & $4(5 \%)$ \\
\hline Infection & $2(3 \%)$ \\
\hline \multicolumn{2}{|l|}{ MRI findings } \\
\hline MTS & $21(27 \%)$ \\
\hline Neoplasia & $24(30 \%)$ \\
\hline Dysplasia & $7(9 \%)$ \\
\hline Nonspecific lesion & $11(14 \%)$ \\
\hline No structural abnormality & $11(14 \%)$ \\
\hline \multicolumn{2}{|l|}{ Noninvasive EEG } \\
\hline Discordant interictal EEG & $11(14 \%)$ \\
\hline Discordant ictal EEG & $5(6 \%)$ \\
\hline \multicolumn{2}{|l|}{ Invasive EEG } \\
\hline SEEG & $3(4 \%)$ \\
\hline Subdural grids & 0 \\
\hline
\end{tabular}

Values are numbers of patients (\%) unless otherwise indicated. Means are presented with SDs.

* Time from seizure onset to surgery.

\section{Surgery}

Patients deemed to be suffering from disabling, medically refractory complex partial seizures originating from a unilateral mesial temporal lobe focus were initially treated with either a transcortical (trans-MTG [middle temporal gyrus]) selective amygdalohippocampectomy (SelAH) ${ }^{22,27}$ or an anterior temporal lobectomy (ATL). SelAH was only offered in patients with clear MRI evidence of mesial temporal sclerosis (MTS) or neoplasm limited to mesial temporal structures (thought to be resectable by this approach) when accompanied by corroborating clinical and electroencephalographic evidence of mesial temporal seizures. Radiographic MTS was defined preoperatively by the presence of hippocampal atrophy, FLAIR/T2 signal change, and/or abnormal internal architecture. SelAH was not performed in patients with MRI evidence of dual pathology (MTS accompanied by temporal neocortical lesion). Details on our surgical approach for SelAH in this series have previously been reported. ${ }^{27}$ In brief, the neu- 
TABLE 2. Preoperative factors and seizure outcomes for 79 patients grouped by surgical procedure

\begin{tabular}{|c|c|c|c|c|}
\hline Group \& Characteristic & $\begin{array}{l}\text { No. of } \\
\text { Pts }\end{array}$ & $\begin{array}{l}\text { Engel } \\
\qquad\end{array}$ & $\begin{array}{l}\text { Engel } \\
>1\end{array}$ & $\begin{array}{c}\mathrm{p} \\
\text { Value }\end{array}$ \\
\hline SelAH & 18 & & & \\
\hline \multicolumn{5}{|l|}{ Side } \\
\hline Left & 7 & $5(72 \%)$ & $2(29 \%)$ & \\
\hline Right & 11 & $3(27 \%)$ & $8(73 \%)$ & 0.145 \\
\hline \multicolumn{5}{|l|}{ Sex } \\
\hline Male & $8(44 \%)$ & $3(38 \%)$ & $5(63 \%)$ & \\
\hline Female & $10(56 \%)$ & $5(50 \%)$ & $5(50 \%)$ & 0.664 \\
\hline \multicolumn{5}{|l|}{ Semiology } \\
\hline Auras & $6(33 \%)$ & $2(33 \%)$ & $4(66 \%)$ & \\
\hline $\begin{array}{l}\text { Complex partial } \\
\text { seizure }\end{array}$ & $13(72 \%)$ & $6(46 \%)$ & $7(54 \%)$ & \\
\hline Generalized seizure & $1(6 \%)$ & $0(0 \%)$ & $1(100 \%)$ & \\
\hline \multicolumn{5}{|l|}{ Clinical findings } \\
\hline $\begin{array}{c}\text { Family history of } \\
\text { epilepsy }\end{array}$ & $3(17 \%)$ & $1(33 \%)$ & $2(66 \%)$ & \\
\hline Febrile seizures & $9(61 \%)$ & $7(78 \%)$ & $2(22 \%)$ & \\
\hline Head trauma & $4(22 \%)$ & $3(75 \%)$ & $1(25 \%)$ & \\
\hline Asphyxia & 0 & & & \\
\hline Infection & $1(6 \%)$ & $0(0 \%)$ & $1(100 \%)$ & \\
\hline \multicolumn{5}{|l|}{ MRI findings } \\
\hline MTS & $13(72 \%)$ & $6(46 \%)$ & $7(54 \%)$ & \\
\hline Neoplasia & $3(17 \%)$ & $2(67 \%)$ & $1(33 \%)$ & \\
\hline Dysplasia & 0 & & & \\
\hline Nonspecific lesion & 0 & & & \\
\hline $\begin{array}{l}\text { No structural abnor- } \\
\text { mality }\end{array}$ & $1(6 \%)$ & $0(0 \%)$ & $1(100 \%)$ & \\
\hline Missing & 1 & $0(0 \%)$ & $1(100 \%)$ & \\
\hline ATL & 61 & & & \\
\hline \multicolumn{5}{|l|}{ Side } \\
\hline Left & $29(48 \%)$ & $23(79 \%)$ & $6(21 \%)$ & \\
\hline Right & $32(52 \%)$ & $24(75 \%)$ & $8(25 \%)$ & 0.767 \\
\hline \multicolumn{5}{|l|}{ Sex } \\
\hline Male & $37(61 \%)$ & $26(70 \%)$ & $11(30 \%)$ & \\
\hline Female & $24(39 \%)$ & $21(88 \%)$ & $3(12 \%)$ & 0.212 \\
\hline \multicolumn{5}{|l|}{ Semiology } \\
\hline Auras & $29(48 \%)$ & $12(41 \%)$ & $17(59 \%)$ & \\
\hline Simple partial seizure & $12(20 \%)$ & $7(58 \%)$ & $5(42 \%)$ & \\
\hline $\begin{array}{l}\text { Complex partial } \\
\text { seizure }\end{array}$ & $48(79 \%)$ & $36(75 \%)$ & $12(25 \%)$ & \\
\hline Generalized seizure & $10(16 \%)$ & $1(10 \%)$ & $9(90 \%)$ & \\
\hline \multicolumn{5}{|l|}{ Clinical findings } \\
\hline $\begin{array}{l}\text { Family history of } \\
\text { epilepsy }\end{array}$ & $17(28 \%)$ & $13(76 \%)$ & $4(24 \%)$ & \\
\hline Febrile seizures & $6(10 \%)$ & $3(50 \%)$ & $3(50 \%)$ & \\
\hline Head trauma & $4(7 \%)$ & $3(75 \%)$ & $1(25 \%)$ & \\
\hline Asphyxia & $4(7 \%)$ & $3(75 \%)$ & $1(25 \%)$ & \\
\hline Infection & $1(2 \%)$ & $0(0 \%)$ & $1(100 \%)$ & \\
\hline
\end{tabular}

CONTINUED IN NEXT COLUMN »
» CONTINUED FROM PREVIOUS COLUMN

TABLE 2. Preoperative factors and seizure outcomes for 79 patients grouped by surgical procedure

\begin{tabular}{|c|c|c|c|c|}
\hline Group \& Characteristic & $\begin{array}{l}\text { No. of } \\
\text { Pts }\end{array}$ & $\begin{array}{l}\text { Engel } \\
\text { I }\end{array}$ & $\begin{array}{c}\text { Engel } \\
>1\end{array}$ & $\begin{array}{c}p \\
\text { Value }\end{array}$ \\
\hline ATL (continued) & 61 & & & \\
\hline \multicolumn{5}{|l|}{ MRI findings } \\
\hline MTS & $9(15 \%)$ & $5(56 \%)$ & $4(44 \%)$ & \\
\hline Neoplasia & $19(31 \%)$ & $17(89 \%)$ & $2(11 \%)$ & \\
\hline Dysplasia & $7(11 \%)$ & $6(86 \%)$ & $1(14 \%)$ & \\
\hline Nonspecific lesion & $11(18 \%)$ & $10(91 \%)$ & $1(9 \%)$ & \\
\hline $\begin{array}{l}\text { No structural abnor- } \\
\text { mality }\end{array}$ & $7(11 \%)$ & $3(14 \%)$ & $4(86 \%)$ & \\
\hline Missing & $8(13 \%)$ & $6(100 \%)$ & $2(0 \%)$ & \\
\hline
\end{tabular}

Pts $=$ patients.

ronavigation system is used to plan the posterior extent of the neocorticectomy in the MTG using a line extending laterally from the lateral mesencephalic sulcus. After the temporal horn is entered, resection of the parahippocampal gyrus, hippocampus, amygdala, and anterior entorhinal cortex occurs (in that order), with the posterior extent of mesial structure resection being defined again by the lateral mesencephalic sulcus. The extent of anterior temporal neocortical resection in the ATL group in this series was planned using neuronavigation to include up to $4 \mathrm{~cm}$ from the temporal tip in dominant resections or up to 5.5 $\mathrm{cm}$ in nondominant resections. Patients in both surgical groups underwent postoperative imaging to verify the extent of resection at 3-6 months. Reoperation was defined as any epilepsy resection after failure of the index operation.

\section{Postoperative Evaluation}

Seizure outcome was assessed using the Engel classification $^{7,9}$ dichotomized for the purposes of analysis as free from disabling seizures (Engel I) versus not (Engel > I), based on the most recent chart note from the treating pediatric neurologist following index (and subsequent) operations. Postoperative MRI was performed in all patients at 3-6 months following index operation. Histopathological analysis was performed by an experienced neuropathologist in all but 11 cases in which en bloc specimens of the mesial temporal structures were not available. Postoperative neuropsychological testing was carried out by an experienced pediatric neuropsychologist (T.S.) 1 year after index and subsequent surgical treatments. The neuropsychological battery included tests of verbal and figural memory as well as the Wechsler Intelligence Scale for Children (WISC; standard scores, mean 100, SD 15), including full-scale IQ, verbal comprehension index (VCI), and perceptual reasoning index (PRI). Verbal memory was summarized using an average (VMA) of T-scores (population mean 50, SD 10) for story memory and delayed word recall for the Rey Auditory Verbal Learning Test. Figure memory was summarized using an average (FMA) of T-scores (population mean 50, SD 10) for memory for faces (from the NEuroPSYchological Assess- 
ment, NEPSY) and the Rey-Osterrieth complex figure, or if memory for faces was not available the average of T-scores for design memory and picture memory (Wide Range Assessment of Memory and Learning) as well as the Rey-Osterrieth complex figure. Preoperative and postoperative group means were compared for each of these 5 scores (IQ, VCI, PRI, VMA, and FMA) separately for patients who initially underwent SelAH $(n=8)$ or ATL $(n=27)$.

\section{Statistical Analysis}

Statistical analysis was performed with Prism software version 7 (GraphPad) and SPSS 24 (IBM Corp.). Fisher's exact test was used to compare rates of seizure freedom after surgery following SAH versus ATL due to the small numbers of patients in some cells. A nonparametric Wilcoxon signed-rank test was used to compare mean preand postoperative neuropsychological testing scores due to the smaller number of patients for whom scores were available among those who initially had a SelAH. A p value $<0.05$ was considered statistically significant throughout. Bonferroni correction was used to correct for multiple comparisons where appropriate.

\section{Results \\ Patient Characteristics}

Seventy-nine patients treated initially with either SelAH $(n=18)$ or ATL $(n=61)$ were included in this retrospective review. The patients' demographic and clinical characteristics are shown in Tables 1 and 2. The mean duration of postoperative surveillance was $5.3 \pm 4$ years (range 1-16 years). The surgical characteristics are shown in Table 3. In the SelAH group, all but 1 patient (whose MRI showed no abnormality) had clear MRI abnormalities consistent with either MTS or mesial temporal neoplasia not extending beyond the expected resection area of a SelAH, without evidence of lateral neocortical abnormalities on MRI. Preoperative MR images were available for review in all but 9 patients ( 1 in the SelAH group and 8 in the ATL group; Table 2), whose imaging studies were available at the time of surgery but no longer archived on our local IMPAX as they were acquired at an outside institution. Postoperative MR images were available for review in all but 5 patients (all of whom underwent index ATL).

\section{Seizure Outcome}

Seizure freedom (Engel I) following initial operation was significantly more likely in the ATL group (47/61, $77 \%$ ) than in the SelAH group (8/18, 44\%; $p=0.017$, Fisher's exact test; Table 3 and Fig. 1). Postoperative morbidity included 10 cases of contralateral superior homonymous quadrantanopia (10/79, 13\%), 1 case of a transient fourth cranial nerve palsy, and 1 case of transient postoperative aphasia. Seizure outcome stratified by pathology is also shown in Table 3.

\section{Neuropsychological Outcome}

Neuropsychological testing was available pre- and postoperatively in 40 patients (9 in the SelAH group and 31 in
TABLE 3. Surgical groups, pathological findings, and seizure outcome for 79 patients with TLE

\begin{tabular}{|c|c|c|c|c|}
\hline Group \& Characteristic & No. of Pts & Engel I & Engel $>1$ & p Value \\
\hline All pts & 79 & $55(70 \%)$ & $24(30 \%)$ & \\
\hline Left & 43 & $27(63 \%)$ & $16(37 \%)$ & \\
\hline Right & 36 & $28(78 \%)$ & $8(22 \%)$ & $0.219^{*}$ \\
\hline SelAH & 18 & $8(44 \%)$ & $10(56 \%)$ & $0.017 \dagger$ \\
\hline Left & 7 & $5(72 \%)$ & $2(29 \%)$ & \\
\hline Right & 11 & $3(27 \%)$ & $8(73 \%)$ & $0.145^{*}$ \\
\hline MTS & 11 & $5(45 \%)$ & $6(55 \%)$ & \\
\hline Neoplasia & 3 & $2(66 \%)$ & $1(33 \%)$ & \\
\hline Gliosis & 0 & $0(0 \%)$ & $0(0 \%)$ & \\
\hline Normal & 1 & $0(0 \%)$ & $1(100 \%)$ & \\
\hline Missing & 3 & $1(33 \%)$ & $2(67 \%)$ & \\
\hline Dysplasia & 0 & & & \\
\hline ATL & 61 & $47(77 \%)$ & $14(23 \%)$ & $0.017 \dagger$ \\
\hline Left & 29 & $23(79 \%)$ & $6(21 \%)$ & \\
\hline Right & 32 & $24(75 \%)$ & $8(25 \%)$ & $0.767^{*}$ \\
\hline MTS & 4 & $0(0 \%)$ & $4(100 \%)$ & \\
\hline Neoplasia & 19 & $17(89 \%)$ & $2(11 \%)$ & \\
\hline Gliosis & 12 & $9(75 \%)$ & $3(25 \%)$ & \\
\hline Normal & 12 & $10(62 \%)$ & $2(17 \%)$ & \\
\hline Missing & 8 & $8(100 \%)$ & $0(0 \%)$ & \\
\hline Dysplasia & 6 & $4(66 \%)$ & $2(33 \%)$ & \\
\hline
\end{tabular}

${ }^{*} p$ values comparing outcomes for sides are for left- versus right-sided operations.

$\dagger p$ values for operation performed are for SelAH versus ATL.

the ATL group) with an average delay of $12 \pm 5$ months after surgery. There were no statistically significant between-groups differences following either SelAH or ATL in verbal memory average (VMA), full-scale IQ, verbal comprehension index (VCI), or perceptual reasoning index (PRI) (nonparametric Wilcoxon signed-rank test). There was a significant improvement in figural memory average (FMA) score after ATL (median postoperative t-score 40.75) compared to before (median preoperative t-score 32.5; Wilcoxon signed-rank test, $Z=147 ; p=0.0005$ ). Similarly, when index dominant and nondominant operations were analyzed separately, there was no statistically significant postoperative between-groups difference for any of the neuropsychological tests (IQ, VCI, PRI, VMA, or FMA), except for a significant improvement in FMA after surgery (median t-score 40.8) in the nondominant ATL group compared to before surgery (median t-score 34.8; Wilcoxon signed-rank test, $\mathrm{Z}=91 ; \mathrm{p}=0.0022$ ). Postoperative neuropsychological data were only available for a subset of the patients who underwent reoperation (8/15), but reoperation was not found to be associated with any case of significant neuropsychological deterioration.

\section{Reoperation}

Reoperation for ongoing or recurrent seizures was significantly more likely after SelAH $(8 / 18,44 \%)$ than after ATL $(7 / 61,11 \% ; p=0.004$; Table 4). Postoperative MRI 


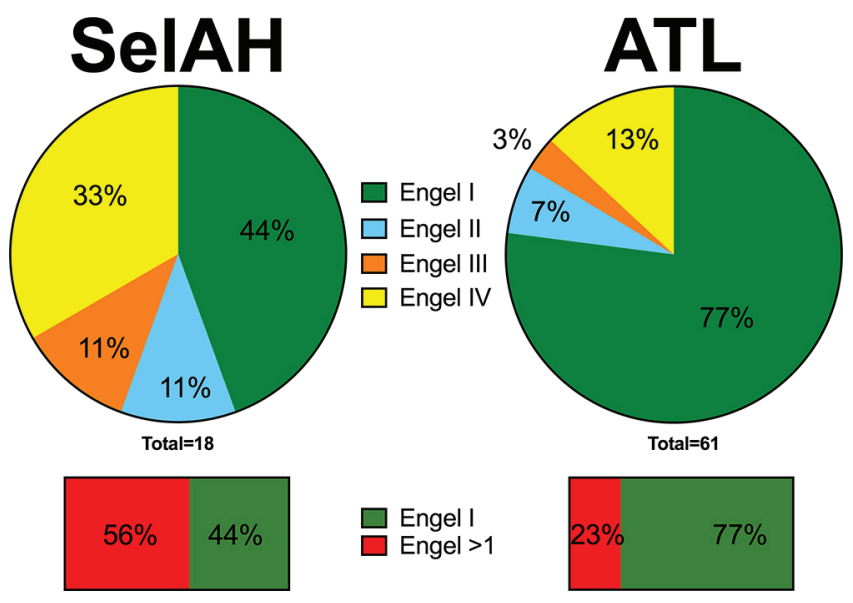

FIG. 1. Engel seizure outcome after index operation in 79 pediatric patients with medically refractory TLE treated initially with selective amygdalohippocampectomy (SelAH, $n=18$ ) or anterior temporal lobectomy (ATL, $n=61$ ). Figure is available in color online only.

studies obtained after the index operation in patients who underwent reoperation were reviewed for completeness of the initial resection (technical description provided in Methods, above), and the resections were considered to be complete in all cases. Reoperation in the form of ATL following failed SelAH was significantly more likely to result in freedom from disabling seizures $(7 / 8,88 \%)$ than was posterior extension after failed $\operatorname{ATL}(1 / 7,14 \% ; \mathrm{p}=$ 0.01 ). Ultimately (including outcome of reoperation in the 15 cases in which it was performed), 58 of 79 patients had an Engel I outcome at the most recent follow-up (mean 5.3 \pm 4 years).

\section{Discussion}

In this study, we found significantly worse seizure control following SelAH, in comparison to ATL, among pediatric patients with medically refractory unilateral TLE. Moreover, reoperation is significantly more likely following initial SelAH, is not associated with incremental neuropsychological deterioration, and frequently results in freedom from disabling seizures. Our data represent a unique contribution to the existing, relatively disparate literature examining postoperative seizure outcome following pediatric SelAH, in that we capture a pragmatic sample of patients with epilepsy of mesial temporal origin based on concordant radiographic, semiologic, and electroencephalographic evidence with 5-year postoperative seizure surveillance. It is important to note that patients who underwent ATL as the index operation are not necessarily equivalent to the SelAH group. Specifically, patients in the ATL group also had concordant preoperative radiographic, semiologic, and electroencephalographic findings of an epileptogenic lesion treatable with surgery, but this lesion would in many cases not be restricted to the mesial temporal structures.

Previous series examining postoperative seizure control after SelAH in pediatric patients have varied considerably, reporting rates of postoperative freedom from disabling seizures ranging from $33 \%$ to $88 \%$., $^{2,-6,8,10,20,23,24}$ For
TABLE 4. Seizure outcome following reoperation in 15 patients with ongoing disabling seizures

\begin{tabular}{lclll}
\hline \multicolumn{1}{c}{ Characteristic } & $\begin{array}{c}\text { No. of } \\
\text { Pts }\end{array}$ & $\begin{array}{c}\text { Engel } \\
\text { I }\end{array}$ & $\begin{array}{c}\text { Engel } \\
>\text { I }\end{array}$ & $\begin{array}{c}\text { p } \\
\text { Value }\end{array}$ \\
\hline ATL following SelAH & $8(44 \%)^{*}$ & $7(88 \%)$ & $1(13 \%)$ & $0.004 \dagger$ \\
\hline MTS & 5 & $5(100 \%)$ & $0(0 \%)$ & \\
\hline Neoplasia & 1 & $0(0 \%)$ & $1(100 \%)$ & \\
\hline Normal & 1 & $1(100 \%)$ & $0(0 \%)$ & \\
\hline Missing & 1 & $1(100 \%)$ & $0(0 \%)$ & \\
\hline Extended resection after ATL & $7(11 \%)^{*}$ & $1(14 \%)$ & $6(86 \%)$ & $0.004 \dagger$ \\
\hline MTS & 1 & $0(0 \%)$ & $1(100 \%)$ & \\
\hline Neoplasia & 1 & $0(0 \%)$ & $1(100 \%)$ & \\
\hline Gliosis & 2 & $1(50 \%)$ & $1(50 \%)$ & \\
\hline Dysplasia & 2 & $0(0 \%)$ & $2(100 \%)$ & \\
\hline Normal & 1 & $0(0 \%)$ & $1(100 \%)$ & \\
\hline
\end{tabular}

${ }^{*} p$ values comparing rate of reoperation following initial SelAH compared to initial ATL (SelAH 8/18 [44\%] vs ATL 7/61 [11\%], $p=0.004$, Fisher's exact test). $\dagger p$ values comparing seizure outcome following reoperation after initial SelAH versus ATL.

example, Datta and colleagues found $3(33 \%)$ of 9 patients to have an Engel I outcome following transcortical SelAH with 1 year of postoperative seizure surveillance. ${ }^{6}$ In a larger series examining 89 pediatric TLE patients followed for nearly 4 years after surgery, Clusmann et al. compared noncontemporaneous cohorts treated with either ATL or more "tailored" resections, reporting combined Engel I and II outcomes as "satisfactory seizure control." They also found significantly worse rates of satisfactory seizure control after SelAH (77\%) than after ATL (94\%; $\mathrm{p}=0.02)$. Their SelAH group $(n=27)$ included 22 patients found to have Ammon's horn sclerosis on histopathology (including 4 patients with additional lateral cortical MRI lesions), 7 patients with tumor, and 2 whose findings were reported as "normal/dysplasia." Mittal et al. found a similar rate of seizure freedom after transcortical SelAH in 10 (77\%) of 13 patients with clear preoperative MRI evidence of unilateral MTS among a cohort of 109 patients followed postoperatively for over 10 years. ${ }^{20}$ These authors also found an ipsilateral reoperation rate for continuing seizures of $21 \%(23 / 109)$, including posterior temporal neocortical resection (15 cases), removal of residual mesial temporal structures ( 3 cases), and treatment of recurrent tumor (5 cases), but they did not contrast reoperation rates following initial ATL versus SelAH. In their reoperated group, $61 \%$ of the patients ultimately achieved seizure freedom, although interval neuropsychological results are not specified. Robinson and coauthors ${ }^{23}$ reported Engel I outcomes in $11(65 \%)$ of 17 patients with 2 years of postoperative follow-up among 22 consecutively operated patients who underwent a transcortical (transparahippocampal) SelAH. Radiographically, their SelAH group $(\mathrm{n}=22)$ was reported to show "hippocampal changes" $(\mathrm{n}=12)$, be normal $(n=7)$, show bilateral abnormalities $(n=2)$, or show a nondescript lesion $(n=1)$. Finally, Beaton and colleagues ${ }^{2}$ reported Engel I outcomes in 7 (88\%) of 8 patients who underwent transsylvian SelAH for hippocampal sclerosis followed for 2 years postoperatively. 
There are important limitations to this retrospective analysis. First, patients were not randomized to surgical treatment arms. During the study period, however, it was our institutional practice to present SelAH as a treatment alternative to ATL, when patients had concordant preoperative findings consistent with a well-localized mesial temporal epileptogenic zone (MRI evidence of MTS or neoplasm limited to mesial temporal structures in all SelAH patients but one-who had preoperative SEEG). Second, multiple pathologies are included in both groups and are not equivalent across groups (Tables 2 and 3). Moreover, SelAH was not performed at our institution in this series until 2003; thus the groups are partially noncontemporary. However, the ATL technique was relatively unchanged during the study period. Third, hippocampal volumetry or T2 relaxometry was not part of our preoperative evaluation. Invasive monitoring in this study was only undertaken in a minority of patients $(n=3)$ who required further evaluation following standard evaluation due to discordant findings. Finally, there are data omissions in this study to acknowledge: 1) surgical pathology was unavailable in 11 cases and 2) pre- and postoperative neuropsychological testing results were only available in a subset of the cohort (9/18 for SelAH cases and 31/61 for ATL cases). Clearly, although there are significant limitations to this and previously reported retrospective analyses, pediatric TLE likely represents an entity that is pathologically distinct from TLE in adults. In particular, pediatric patients with findings of MTS on MRI (unlike adults) may have a wider range of pathology, which may include additional MRI-invisible lesions not confined to mesial structures.,21 Reconciling these results in the context of previous work is challenging given the variability of patient selection, the duration of postoperative follow-up, and small sample size in many studies.

\section{Conclusions}

In summary, SelAH among pediatric patients with medically refractory unilateral TLE yields significantly worse rates of seizure control than ATL, with no difference in neuropsychological outcomes. Reoperation is significantly more likely following SelAH, is not associated with incremental neuropsychological deterioration, and frequently results in freedom from disabling seizures. These results are significant in that they argue against using SelAH for pediatric TLE surgery.

\section{Acknowledgments}

This work was supported by the Killam Trust Doctoral Scholarship and the Clinical Investigator Program (C.A.E.) at the University of Alberta.

We extend special thanks to Janet Edgerton for contributions to the compilation of the neuropsychological test results.

\section{References}

1. Arruda F, Cendes F, Andermann F, Dubeau F, Villemure JG, Jones-Gotman M, et al: Mesial atrophy and outcome after amygdalohippocampectomy or temporal lobe removal. Ann Neurol 40:446-450, 1996

2. Beaton AE, Durnford A, Heffer-Rahn PE, Kirkham F, Griffin
A, Gray WP: Transsylvian selective amygdalohippocampectomy in children with hippocampal sclerosis: seizure, intellectual and memory outcome. Seizure 21:699-705, 2012 (Erratum in Seizure 22:411, 2013)

3. Benifla M, Rutka JT, Otsubo H, Lamberti-Pasculli M, Elliott I, Sell E, et al: Long-term seizure and social outcomes following temporal lobe surgery for intractable epilepsy during childhood. Epilepsy Res 82:133-138, 2008

4. Clusmann H, Kral T, Gleissner U, Sassen R, Urbach H, Blümcke I, et al: Analysis of different types of resection for pediatric patients with temporal lobe epilepsy. Neurosurgery 54:847-860, 2004

5. Clusmann H, Schramm J, Kral T, Helmstaedter C, Ostertun B, Fimmers R, et al: Prognostic factors and outcome after different types of resection for temporal lobe epilepsy. J Neurosurg 97:1131-1141, 2002

6. Datta A, Sinclair DB, Wheatley M, Jurasek L, Snyder T, Quigley D, et al: Selective amygdalohippocampectomy: surgical outcome in children versus adults. Can J Neurol Sci 36:187-191, 2009

7. Durnford AJ, Rodgers W, Kirkham FJ, Mullee MA, Whitney A, Prevett M, et al: Very good inter-rater reliability of Engel and ILAE epilepsy surgery outcome classifications in a series of 76 patients. Seizure 20:809-812, 2011

8. Dwivedi R, Ramanujam B, Chandra PS, Sapra S, Gulati S, Kalaivani M, et al: Surgery for drug-resistant epilepsy in children. N Engl J Med 377:1639-1647, 2017

9. Engel J Jr (ed): Surgical Treatment of the Epilepsies, ed 2. New York: Raven Press, 1993

10. Englot DJ, Han SJ, Rolston JD, Ivan ME, Kuperman RA, Chang EF, et al: Epilepsy surgery failure in children: a quantitative and qualitative analysis. J Neurosurg Pediatr 14:386-395, 2014

11. Goldstein LH, Polkey CE: Short-term cognitive changes after unilateral temporal lobectomy or unilateral amygdalohippocampectomy for the relief of temporal lobe epilepsy. J Neurol Neurosurg Psychiatry 56:135-140, 1993

12. Helmstaedter C, Richter S, Röske S, Oltmanns F, Schramm J, Lehmann TN: Differential effects of temporal pole resection with amygdalohippocampectomy versus selective amygdalohippocampectomy on material-specific memory in patients with mesial temporal lobe epilepsy. Epilepsia 49:88-97, 2008

13. Hosoyama H, Matsuda K, Mihara T, Usui N, Baba K, Inoue Y, et al: Long-term outcomes of epilepsy surgery in 85 pediatric patients followed up for over 10 years: a retrospective survey. J Neurosurg Pediatr 19:606-615, 2017

14. Kirkpatrick PJ, Honavar M, Janota I, Polkey CE: Control of temporal lobe epilepsy following en bloc resection of lowgrade tumors. J Neurosurg 78:19-25, 1993

15. Lah S: Neuropsychological outcome following focal cortical removal for intractable epilepsy in children. Epilepsy Behav 5:804-817, 2004

16. Lee YJ, Kang HC, Bae SJ, Kim HD, Kim JT, Lee BI, et al: Comparison of temporal lobectomies of children and adults with intractable temporal lobe epilepsy. Childs Nerv Syst 26:177-183, 2010

17. Lee YJ, Lee JS: Temporal lobe epilepsy surgery in children versus adults: from etiologies to outcomes. Korean J Pediatr 56:275-281, 2013

18. Duchowny M, Levin B, Jayakar P, Resnick T, Alvarez L, Morrison G, et al: Temporal lobectomy in early childhood. Epilepsia 33:298-303, 1992

19. Meyer FB, Marsh WR, Laws ER Jr, Sharbrough FW: Temporal lobectomy in children with epilepsy. J Neurosurg 64:371-376, 1986

20. Mittal S, Montes JL, Farmer JP, Rosenblatt B, Dubeau F, Andermann F, et al: Long-term outcome after surgical treatment of temporal lobe epilepsy in children. J Neurosurg 103 (5 Suppl):401-412, 2005 
21. Mohamed A, Wyllie E, Ruggieri P, Kotagal P, Babb T, Hilbig A, et al: Temporal lobe epilepsy due to hippocampal sclerosis in pediatric candidates for epilepsy surgery. Neurology 56:1643-1649, 2001

22. Olivier A: Transcortical selective amygdalohippocampectomy in temporal lobe epilepsy. Can J Neurol Sci 27 (Suppl 1):S68-S76, S92-S96, 2000

23. Robinson S, Park TS, Blackburn LB, Bourgeois BF, Arnold ST, Dodson WE: Transparahippocampal selective amygdalohippocampectomy in children and adolescents: efficacy of the procedure and cognitive morbidity in patients. J Neurosurg 93:402-409, 2000

24. Ryu SY, Lim EY, Na S, Shim YS, Cho JH, Yoon B, et al: Hippocampal and entorhinal structures in subjective memory impairment: a combined MRI volumetric and DTI study. Int Psychogeriatr 29:785-792, 2017

25. Schmidt D, Stavem K: Long-term seizure outcome of surgery versus no surgery for drug-resistant partial epilepsy: a review of controlled studies. Epilepsia 50:1301-1309, 2009

26. Sinclair DB, Aronyk K, Snyder T, McKean J, Wheatley M, Bhargava R, et al: Pediatric temporal lobectomy for epilepsy. Pediatr Neurosurg 38:195-205, 2003

27. Wheatley BM: Selective amygdalohippocampectomy: the trans-middle temporal gyrus approach. Neurosurg Focus 25(3):E4, 2008

28. Wieser HG, Ortega M, Friedman A, Yonekawa Y: Long-term seizure outcomes following amygdalohippocampectomy. J Neurosurg 98:751-763, 2003

29. Wyllie E, Comair YG, Kotagal P, Bulacio J, Bingaman W, Ruggieri P: Seizure outcome after epilepsy surgery in children and adolescents. Ann Neurol 44:740-748, 1998

\section{Disclosures}

The authors report no conflict of interest concerning the materials or methods used in this study or the findings specified in this paper.

\section{Author Contributions}

Conception and design: Sinclair, Elliott, Wheatley. Acquisition of data: Sinclair, Elliott, Broad, Narvacan, Urlacher. Analysis and interpretation of data: all authors. Drafting the article: Sinclair, Elliott, Broad, Steve, Wheatley. Critically revising the article: Sinclair, Elliott, Steve, Urlacher, Wheatley. Reviewed submitted version of manuscript: Sinclair, Elliott, Broad, Narvacan, Steve, Snyder, Wheatley. Approved the final version of the manuscript on behalf of all authors: Sinclair. Statistical analysis: Elliott. Study supervision: Sinclair.

\section{Supplemental Information \\ Previous Presentations}

Portions of this work were presented in abstract form at the Annual Congress of the Canadian Neurological Sciences Foundation, June 20-23, 2017, in Victoria, BC, Canada, and the American Epilepsy Society annual meeting, December 2-5, 2017, in Washington, DC.

\section{Correspondence}

D. Barry Sinclair: Edmonton Clinic Health Academy, Edmonton, AB, Canada.barry.sinclair@albertahealthservices.ca. 